\title{
Acceptability of Lean Six Sigma in a Developing Economy: Results from Exploratory Research in Nigerian Consulting Companies
}

\author{
Oviri Umude-Igbru ${ }^{1}$ \\ Brian Price ${ }^{2}$ \\ School of Engineering and Applied Science \\ Aston University \\ Birmingham, B4 7ET, United Kingdom \\ umudeioc@aston.ac.uk, B.J.PRICE@aston.ac.uk
}

\begin{abstract}
The application of Lean Six Sigma (LSS) varies in different regions of the world in terms of both level of understanding and acceptability. Employing a qualitative methodological approach, this paper aims to explore factors hindering the acceptability of the LSS initiative in organizations and list factors required for successful application and implementation in a developing economy from the perspective of LSS consultants. Using Nigeria as a case study, primary data were collected though a number of semi-structured interviews with representatives of leading continuous improvement consultancy firms in Nigeria. Finding draws out links between major factors such as drivers and motivation, LSS performance, marketability and challenges to the acceptability and applicability of LSS in Nigeria. Further findings highlight major factors such as lack of management buy-in, level of awareness, certification driven market, Nigerian environment and culture, etc as problems that hinder successful implementation of LSS in Nigeria. This paper contributes to the theoretical foundation of critical success factors required for the implementation of Lean Six Sigma, with results from the experience of a developing economy.
\end{abstract}

Keywords - Continuous Improvement, Lean Six Sigma, Developing Countries, Nigeria

\section{INTRODUCTION}

Organizations typically are setup with an overall aim to make profits for its shareholders, through the provision of products and services. However, competition among organizations has become a worldwide challenge, with organizations adopting different strategies for business survival. The role of quality management in ensuring competitiveness cannot be overemphasized. Arguably, the effectiveness of traditional management tools and mind-sets in relation to current business demands could be questioned [2, $3]$. This is as a result of the implementation of continuous improvement initiatives by organizations on its processes. Investigations are still ongoing on the applicability of promising quality management and continuous improvement practices in different sectors and geographies characterized with distinctive cultures [4]. The knowledge transfer of continuous improvement professionals (Consultants) within industries in different sectors and cultures to the applicability of the LSS initiative cannot be overemphasized. Their awareness of the local conditions for which these organizations operate further promotes the applicability and acceptability of continuous improvement initiatives.

Lean Methodology and the Six Sigma as highlighted by leading continuous improvement professionals are examples of the most current and successfully proven concepts in the field of quality management [5-7]. The application of these methodologies has given rise to tremendous research that seeks to identify its success factors [5]. The six sigma methodology, pioneered by Motorola in the 1990s has over the years proven to be a successful management tool [8]. Lean methodology on the other hand has established itself through the elimination of waste and increased process flow within a manufacturing and production setting [9]. The last decade has provided a synergetic approach of both methodologies to form the Lean Six Sigma (LSS) initiative. The rationale behind this integration is to maximise the benefits of the principles each methodology accords. The success of the LSS initiative has been backed up by both theoretical and practical research [10, 11]. Its role in maintaining competitive advantage has been firmly established [12]. However, it is arguable that empirical evidence to support this view is drawn heavily from researches carried out in developed countries. Little comparable research has been carried out on the acceptability and the practicability of the LSS initiative in organizations in developing countries.

This paper seeks to investigate related issues to the acceptability and application of the Lean Six Sigma initiative in a developing country. The paper begins with an overview 
and also a review of literature on the concept of Lean Six Sigma. The adopted methodology is identified thereafter and the results from the case study of this research are presented. The final section of this paper provides conclusions based on the research findings.

\section{LITERATURE REVIEW}

\section{A. Emergence of Lean Six Sigma}

The origin of the LSS initiative was borne from the integration of the two quality management methodologies of Lean Manufacturing and Six Sigma. These concepts are synergistically aligned to increase the scope of improvements achieved by either methodology alone [10]. These methodologies have traditionally been categorized separately, as they are characterized by differing practices. The last decade however, has promoted a synthesis of both concepts [13]. The Lean Methodology focuses on the identification of non-value added activities and also the reduction of waste within a production process, while Six Sigma on the other hand focuses on the reduction of process variation [4]. The integration of both philosophies is facilitated by their underlying principle of waste reduction, taking into consideration the effective aspects of each methodology to form a better approach [14].

The perception of the LSS initiative by organizations is viewed from different perspectives. In one scenario, LSS is viewed as a full organization-wide integration of both methodologies of Lean and Six Sigma while another scenario perceives LSS as the adoption of both methodologies in parallel as they commend each other [15]. Either way, the benefits of implementation of both concepts is achieved based on the needs of the organization. According to Assarlind, Gremyr [15], the integration of both methodologies typically involves the exchange of principles, tools and philosophies each represents. Beyond the tremendous benefits achieved by each methodology [16, 17], within the Lean concept, statistical process control cannot be achieved, while the Six Sigma methodology on the other hand has its limitations in relation to improvements in production process speed [4]. According to Kumar, Antony [18], the competitive nature of today's business environment requires the combination of both concepts as an isolated implementation fails to eliminate effectively the problems organizations face. To this end, the synergetic approach between their functionalities is seen as providing additional value to the organization as a whole. The figure below indicates which areas of business operation are most impacted by Lean and Six Sigma.

\begin{tabular}{lcc}
\hline \multicolumn{1}{c}{ OBJECTIVES/PROBLEMS } & LEAN & SIX SIGMA \\
\hline Focuses on customervaluestream & $Y$ & $X$ \\
\hline Focuses on creatinga visual workplace & $Y$ & $X$ \\
\hline Creates standard worksheets & $Y$ & $X$ \\
\hline Attacks work-in-processinventory & $Y$ & $X$ \\
\hline Focuses on good house keeping & $Y$ & $X$ \\
\hline Process control planningand monitoring & $X$ & $Y$ \\
\hline Focuses on reducing variation and achieveuniform process outputs & $X$ & $Y$ \\
\hline Focuses heavily on the application of statistical toolsand techniques & $X$ & $Y$ \\
\hline Employs a structured, rigorous and well planned problem solving methodology & $X$ & $Y$ \\
\hline Attacks waste due to waiting, over processing, motion, over production, etc. & $Y$ & $X$ \\
\hline
\end{tabular}

Figure 1 Synergetic Approach to Lean and Six Sigma [1]

\section{B. Application of Lean Six Sigma}

The applicability of the LSS initiative is dependent on the specific needs of the organization as characterized by the competitive business environment. The application of these quality management methods by organizations to eliminate waste and reduce operational ineffectiveness requires top management commitment and involvement in order to provide the proper environment for implementation [18]. In the case of Lean Six Sigma, Psychogios and Tsironis [4] described it as an unstandardized procedure with its applicability being experienced by organizations in various sectors. However, the theoretical debate of the applicability of the Lean Six Sigma within organizations of different sectors provides a structured approach to the implementation of the concept as presented through the identification of the Critical Success Factors (CSF's) [11, 19]. According to Rockart [20] CFS “ for any business, are the limited number of results, if they are satisfactory will ensure successful competitive performance for the organization". Research work by Psychogios and Tsironis [4] on the role of CSF's in LSS implementation established two major aspects for which the concept could be applied. They are the Management-oriented and the Human Resource-oriented factors. The former in this context represents organization-wide factors relating to customer satisfaction, strategy and selection of projects. The latter represents HR functions as related to the factors of training, quality culture, leadership, etc. This further corroborates the identified CSF's around the LSS literature [19, 21, 22], thereby promoting the LSS initiatives for organizations in different sectors and geographies; be it in a developing or developed economy.

\section{RESEARCH METHODOLOGY}

This study employs a case study research strategy. Previous research has argued the need to employ qualitative research methods in dealing with implementation issues within the field of engineering and operations management [4, 23]. Opinions and beliefs around the adoption and 
acceptability of management practices are not always amenable to quantitative approaches, however a qualitative methodology can provide useful insights into the motivations and behaviors related to quality initiatives [24, 25]. This case study focuses on the acceptability of the Lean Six Sigma initiative with a developing economy. As Yin [26] explains, a case study approach involves an empirical inquiry aimed at conducting a thorough investigation within a real, natural setting of an organization or context for an observed phenomenon.

In capturing primary data, interviews were employed rather than surveys as it allows for an in-depth investigation of the observed case [27]. The sample of organizations was drawn from consultant companies around the field of Lean Six Sigma, chosen based on their level of experience and penetration in the Nigerian market. Judging from their level of knowledge and expertise in continuous improvement initiatives, LSS consultants were sought to be the most appropriate source of data collection as opposed to other stake holders in the adoption of LSS. As this paper aims to review the acceptability of the LSS initiative in Nigeria, the unique perspective of LSS consultants with both strengths and weaknesses provides a clear picture of happenings within the industry. Interviews were conducted with representatives of six (6) major consultancy firms in Nigeria. The obvious bias to this sample however could be categorized in their need to sell the LSS initiative. Measures however, were created when developing the research instrument to eliminate such bias. Further ethical issues and concerns were considered as the researcher sought approval from respondents. Data were collected through semi-structured interviews as the provided respondents the opportunity to give detailed insights to the observed phenomenon [25]. Data were transcribed and subjected to content analysis as a means of building the case study.

\section{RESEARCH FINDINGS}

\section{A. The Case Study}

As a typical example of a developing and emerging economy, Nigeria is identified as a major driver of economic growth and development within the African continent judging from its biggest strengths, its economic size and strong revenue base generated from the oil and gas sector, manufacturing, finance, telecoms and services industries [28, 29]. The Nigerian economic environment is characterized by these sectors which contribute to its industrial growth that has in recent years been spurred by a rapid industrialization of all facets of Nigeria economy which currently ranks as Africa's biggest economy [30].

\section{B. LSS acceptability in context}

Table 1 below highlights major factors inherent within the Nigerian industry as they affect the acceptability of the Lean Six Sigma initiative. Drawn from the study, thematic factors with corresponding coding were highlighted as a basis for analysis.

The first identified theme is related to the Drivers and motivation for LSS implementation in Nigeria. This provides the rationale and need for organizations to embrace the principles of continuous improvement. It is imperative for learning organizations to identify the sector drivers and prerequisites for the implementation of LSS as it allows for knowledge sharing between industry stakeholders. As to Performance, the current state of the Nigerian industry is not well established, thereby exposing opportunities for improvements. Third is the Marketability of the LSS initiative, which represents the role of LSS professionals and consultants in the awareness journey. The last theme highlights Challenges that limits the acceptability of the LSS initiative within the Nigerian environment. The synergy of these themes provides an overview of the overall aim of this research, proffering answers to questions asked by researchers today.

TABLE 1

CLASSIFICATION OF MAJOR FACTORS

\begin{tabular}{|c|c|c|c|}
\hline $\begin{array}{c}\text { Drivers and } \\
\text { motivation }\end{array}$ & Performance & Marketability & Challenges \\
\hline $\begin{array}{c}\text { Industry sector } \\
\text { drivers }\end{array}$ & $\begin{array}{c}\text { LSS Nigeria } \\
\text { Industry } \\
\text { rating }\end{array}$ & $\begin{array}{c}\text { Organizations } \\
\text { acceptability }\end{array}$ & $\begin{array}{c}\text { Low awareness } \\
\text { level/ knowledge }\end{array}$ \\
\hline $\begin{array}{c}\text { Multinational } \\
\text { companies } \\
\text { implementation }\end{array}$ & $\begin{array}{c}\text { LSS } \\
\text { Sustainability }\end{array}$ & $\begin{array}{c}\text { Certification- } \\
\text { driven market }\end{array}$ & $\begin{array}{c}\text { Nigerian } \\
\text { environment and } \\
\text { culture }\end{array}$ \\
\hline $\begin{array}{c}\text { Process and } \\
\text { productivity } \\
\text { improvements }\end{array}$ & $\begin{array}{c}\text { LSS } \\
\text { perceptivity/ }\end{array}$ & & $\begin{array}{c}\text { Employee } \\
\text { commitment }\end{array}$ \\
\hline & & & $\begin{array}{c}\text { Management buy-in } \\
\text { dion of Quality- } \\
\text { driven culture }\end{array}$ \\
\hline
\end{tabular}

Further tables below display indicative statements generated from interviews with representatives of LSS consultancy companies in Nigeria. These are categorized into themes adopted from literature linked to the acceptability of continuous improvement initiatives.

With respect to the to the Nigerian context, the leading sector drivers for the implementation of the LSS initiative are the manufacturing and production industry, telecommunications and the financial sectors respectively. Identified as the backbone of the nation's economy, these industrial sectors contribute about $65.3 \%$ to the GDP [30, 31]. 
The penetration of multinational companies within the industry has necessitated the need for organizations to adopt means to ensure competitive advantage.

TABLE 2 DRIVERS AND MOTIVATION FOR LSS IN NIGERIA

\begin{tabular}{ll} 
Open coding & Qualitative evidence \\
\hline $\begin{array}{l}\text { Industry sector } \\
\text { drivers }\end{array}$ & $\begin{array}{l}\text { 'I will say the industries that patronizes LSS most } \\
\text { in Nigeria are the Multinationals mainly in the area } \\
\text { of manufacturing, oil and gas and } \\
\text { telecommunications, but mostly the multinationals' } \\
\text { (Accenture global consulting) }\end{array}$ \\
$\begin{array}{l}\text { 'The manufacturing and production industry } \\
\text { patronizes the most' (Lean Sigma Concepts) }\end{array}$
\end{tabular}

Multinational companies implementation

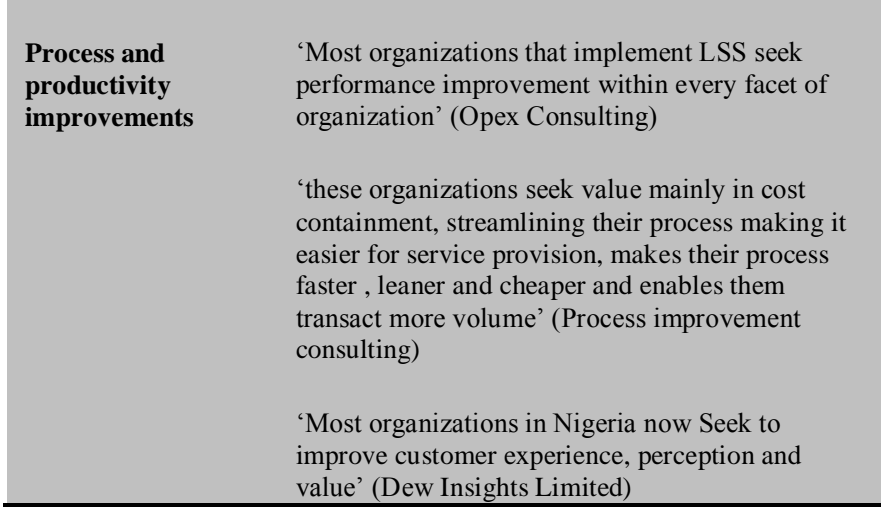

Emphases from respondents on the drivers for implementation are characterized by the need for organizations in Nigeria to embrace concepts and initiatives adopted by their parent companies in developed countries. As the Nigerian industrial sector is mainly characterized with organizations categorized into multinationals and indigenous companies, it is expected that the influx of these experienced companies would have its impact on growing indigenous companies, particularly small and medium scale enterprises (SME's) in relation to knowledge transfer of continuous improvement initiatives. However this is far from the case. The Process and productivity improvements which these organizations seek to achieve are often not realized. The theoretical background of these indigenous organizations with respect to initiatives such as LSS, without practical hands-on experience hinders successful implementation. Experts from interviews have emphasized that many organizations are hoping to reap benefits of Lean Six Sigma. However, this is not easily achieved. The question then arises as to the organizations willingness to adhere to the pre-requisites for implementation. Most multinational companies however are structured to embrace change and will require a structured approach to LSS implementation, taking into account the environment to which they operate.

The performance of LSS currently in Nigeria has been identified as very poor, with an average performance rating of about 3.5 on a 10point scale. It is expected that the dominance of multinational companies will drive the industrial awareness to an optimum mark, but the level of integration is found to be in its infancy. Just like any other quality management program, there is a belief that the sustainability of the LSS initiative over time may come into question. As the sustainability of LSS relies on a critical review of core organizational values, it is expected that organizations hoping to reap the benefits of implementation seek ways to embrace beliefs and principles aimed to create an environment of continuous improvement. Organizational core values and principles should be tailored towards a long term strategy that incorporates corporate culture and commitment towards the principles of LSS. This will eliminate the issue of management being disappointed with LSS implementation due to the low competency level. However, the quick-fix culture for which the Nigerian industry is synonymous further hinders the performance of the LSS initiative in Nigeria in relation to its sustainability. Identified as a major problem to the sustainability of the initiative, the attitude towards LSS by organizations is viewed as another "management fad" that will run its course over time. A link between the sustainability and the perception of the LSS initiative in the Nigerian industry is drawn as both themes identify the theoretical approach which the concept is based, eliminating the need for commitment to full implementation. From the view of multinational organizations, the reverse is often the case due to the level of awareness within organizations. The local or indigenous companies on the other hand struggle with its performance due to the mind-set previously identified. It is interesting however, that most organizations within this environment welcome the idea of quality improvement initiatives that could generate rapid improvements for their company. The struggle lies with full integration with the organizational culture. This provides hope for the future applicability of the LSS initiative 
within organizations in different business region, as far as the pre-requisites for implementation are understood and met.

TABLE 3 LSS PERFORMANCE IN NIGERIA

\begin{tabular}{|c|c|}
\hline Open coding & Qualitative evidence \\
\hline \multirow[t]{3}{*}{$\begin{array}{l}\text { LSS Nigeria } \\
\text { Industry } \\
\text { rating }\end{array}$} & $\begin{array}{l}\text { On a scale of } 1 \text { to } 10 \text { where one stands for poor and } 10 \\
\text { excellent, I will rate it at a } 4 \text { because it's not really } \\
\text { grounded within the Nigerian industry but there is general } \\
\text { improvement (Dew Insights Limited) }\end{array}$ \\
\hline & $\begin{array}{l}\text { The level of implementation is at its infancy level and on a } \\
\text { scale of } 1 \text { to } 10 \text { with one been poor and } 10 \text { been excellent I } \\
\text { will rate it } 3 \text { volume' (Process improvement consulting) }\end{array}$ \\
\hline & $\begin{array}{l}\text { On a scale of } 10 \text { I would rate the implementation as a } 4 \\
\text { because the implementation in Nigeria industries is very } \\
\text { poor and even those employees who have been trained have } \\
\text { difficulty in applying the training because the organization } \\
\text { do not seek to fully integrate it (Acceltage Consulting) }\end{array}$ \\
\hline \multirow[t]{2}{*}{$\begin{array}{l}\text { LSS } \\
\text { Sustainability }\end{array}$} & $\begin{array}{l}\text { 'There are always people and organizations that take LSS } \\
\text { as a Fad and feel it will fade overtime'. also, 'There have } \\
\text { been situations in which professionals that have trained on } \\
\text { LSS as green or black belts but have not been mentored on } \\
\text { a project or implemented a project and now work within } \\
\text { the organizations and are unable to deliver. This has a } \\
\text { resulting effect with management resenting LSS } \\
\text { implementation (Dew Insights Limited) }\end{array}$ \\
\hline & $\begin{array}{l}\text { 'Most organizations seek short turn around investment time } \\
\text { and are not bothered about the long term improvement. In } \\
\text { as much as there are quick wins associated with Lean Six } \\
\text { Sigma, the major effect on the organization is long term } \\
\text { sustenance' (Lean Sigma Concepts) }\end{array}$ \\
\hline \multirow[t]{3}{*}{$\begin{array}{l}\text { LSS } \\
\text { receptivity/ } \\
\text { perception }\end{array}$} & $\begin{array}{l}\text { Most of them feel it's mainly theories especially within the } \\
\text { manufacturing industries particularly the SME's and the } \\
\text { aviation industries who are supposed to be the drivers are } \\
\text { mainly lagging behind (Acceltage Consulting) }\end{array}$ \\
\hline & $\begin{array}{l}\text { The Industry's Perception to LSS also is divided between } \\
\text { Multinationals and Indigenous. The Indigenous companies } \\
\text { don't see the value and see it more just as a theory and } \\
\text { most don't see how it adapts to their system (Lean Sigma } \\
\text { Concepts) }\end{array}$ \\
\hline & $\begin{array}{l}\text { There is a high level of interest of recent but understanding } \\
\text { the LSS concept by organizations has been difficult with } \\
\text { most organizations viewing it as a framework that can be } \\
\text { used to achieve rapid improvement and cost reduction } \\
\text { without seeing the underlying benefit of integrating it into } \\
\text { organizations culture (Dew Insights Limited) }\end{array}$ \\
\hline
\end{tabular}

The quest for high profits has led organizations in Nigeria to cut back on spending resources on quality improvement programs such as LSS [32]. Culturally, the concept of formal change management is unfamiliar to indigenous companies in Nigeria as the business environment is fraught with different kinds of risk. Rather than assign resources to improvement programs such as LSS, organizations would rather employ individuals who have been certified in LSS. Unfortunately, these often possess little or no practical experience to drive their LSS projects.

TABLE 4

LSS MARKETABILITY IN NIGERIA

\begin{tabular}{cc}
\hline Open coding & \multicolumn{1}{c}{ Qualitative evidence } \\
\hline $\begin{array}{c}\text { Organizations } \\
\text { acceptability }\end{array}$ & $\begin{array}{c}\text { The major challenge is from the perception of the } \\
\text { people and the cultural differences of the } \\
\text { organizations. Many think it's just a concept that } \\
\text { cannot be translated to something realistic (Lean } \\
\text { Sigma Concepts) }\end{array}$ \\
$\begin{array}{c}\text { There are always people and organizations that } \\
\text { take LSS as a Fad and feel it will fade overtime, } \\
\text { also there are organizations who due to inability to } \\
\text { sustain LSS or financial constraints have } \\
\text { completely ignored it (Dew Insights Limited) } \\
\text { The LSS initiative often gets rejected primarily } \\
\text { because of the level of awareness as organizations } \\
\text { felt it sounded complicated and technical (Opex } \\
\text { Consulting) }\end{array}$
\end{tabular}

Certification

driven market
Our vision is for a company to adopt LSS as their continuous improvement platform instead of their workers obtaining certification but cannot practice or implement the initiative (Process improvement consulting)

\footnotetext{
Organizations are mainly concerned with the certification process and improving organizational image and brand but not concerned with change management which LSS offers (Lean Sigma Concepts)

We have so many people with LSS certifications but in terms of practical knowledge, these organizations are found lacking. (Dew Insights Limited)
}

The marketability of LSS in Nigeria has been affected by multinational organizations. As highlighted by some of the interviewees, these organizations are typically larger in size and possess more resources to drive both the process and the individuals linked with the LSS projects. This is so because they understand the need for training. This situation is not the same with indigenous Nigerian organizations where management feels that training of personnel is expenditure and not an investment. A major barrier to LSS implementation lies in the inability of indigenous companies to view LSS as a long term project involving the entire business function, aimed at sustaining organizational growth and improvements, rather as a fad as highlighted by the respondents. As posited by one of the interviewees, the quest for certifications has befuddled the implementation of LSS in Nigeria. The more certificates individuals working in an organization possess, the easier it is for that organization to attract investors as it is erroneously 
assumed that such organization have built competence. We thus have organizations chasing the image of capability, rather than substantive real expertise. Implementation process is usually a challenge in Nigeria and elsewhere across the globe. The certification-driven culture which the Nigerian business environment is characterized with hinders the implementation of the LSS initiative and also eliminates value creation.

Managing organizational culture is a difficult process as it entails changing the ways things are ordinarily done and possibly seeking a change in behaviors, attitudes and beliefs. Implementing LSS within an organization may entail an organization building an entirely new support system for the business operations and changing personnel mindset and attitudes towards its functions. This can be a daunting task.

TABLE 5

CHALLENGES FACED BY NIGERIAN ORGANIZATIONS TO LSS

\begin{tabular}{cc} 
Open coding & Qualitative evidence \\
\hline $\begin{array}{c}\text { Low awareness } \\
\text { level/ } \\
\text { knowledge }\end{array}$ & $\begin{array}{c}\text { A general knowledge of LSS is inherent within the } \\
\text { Nigerian industry. However, in terms of } \\
\text { implementation, there is little or no knowledge. } \\
\text { It's mostly theoretical. (Acceltage Consulting) }\end{array}$ \\
LSS is still at its developmental stage. No big \\
awareness of LSS within the past years (Process \\
improvement consulting)
\end{tabular}

Nigerian environment and culture
One of the biggest challenges is Change, change in mind-set, the paradigm shift. There is need for a change in our culture; Nigeria practices a culture of waste. (Accenture global consulting)

The Nigerian environment deals with quick wins and quick fix so the ability of picking right projects that shows visible benefits of LSS is crucial (Dew Insights Limited)

the Nigeria culture heavily limits the ability of organizations to buy into the Lean Six Sigma concept as the culture encourages waste (Lean Sigma Concepts)

$\begin{gathered}\text { Leadership } \\ \text { culture }\end{gathered}$
$\begin{gathered}\text { It boils down on Leadership culture; the leadership } \\ \text { culture really in Nigeria will rather spend money } \\ \text { on public relations than on their internal process. } \\ \text { There is a bad leadership culture in Nigeria } \\ \text { (Acceltage Consulting) }\end{gathered}$

Employee commitment
In an organization where I instituted LSS, ten (10) management staffs where trained to green belt level and were given projects; half did not complete their projects because there were other things competing for their attention in terms of work-load so from the beginning they did not attach much importance to LSS and its benefit to even their work process. (Process improvement consulting)

\begin{tabular}{cc}
\hline buy-in & $\begin{array}{c}\text { management to buy into LSS is a major problem } \\
\text { in Nigeria (Accenture global consulting) }\end{array}$ \\
$\begin{array}{c}\text { Lack of } \\
\text { cultity-driven }\end{array}$ & $\begin{array}{c}\text { There are organizations dedicated to quality } \\
\text { control and quality assurance but organizations do } \\
\text { not see quality as a way of life or as part of their } \\
\text { organizational culture. Their quality knowledge } \\
\text { does not spread throughout the organization and } \\
\text { it's not integrated as an organization culture (Opex } \\
\text { Consulting) }\end{array}$ \\
\\
$\begin{array}{c}\text { Some organizations care more about certifications } \\
\text { than integrating quality into their organizational } \\
\text { culture (Process improvement consulting) }\end{array}$ \\
\hline
\end{tabular}

The implementation and practice of LSS in Nigeria as highlighted by respondents has been slowed down and sometimes out right hindered by the factors stated above. Change in organizational culture and employee attitude can be a daunting task. As identified by [33] one major barrier to implementing change management is organizational culture, which is inherent in LSS implementation in Nigeria as organizations exist in an environment and culture that encourages waste. Most organizations pass through the process of cultural change but meet with strong resistance from employees. Employee commitment in the continuous improvement journey is an important factor to ensure the sustainability of the program as it promotes innovation within the organization. [34] revealed four common reasons why organizations oppose change including: parochial self-interest, low tolerance for change, lack of trust, different assessments of the need for change. These factors identified by Kotter and Schlessinger is top-down (i.e it affects management as well as staff within the organization). The table 5 above exposes that the Nigerian industries are reactive in nature and rather than proactively pursue initiatives that would drive the goals and objectives of the organization, they would rather react to situations as they occur. The leadership culture that promotes a reactive approach to problem-solving hinders the sustainability of continuous improvement initiatives. Being proactive means taking some advance steps in anticipation of the occurrence of an event and there are usually costs associated with such gestures, however, the benefits are not immediate seen and quantified. The concept of pro-activeness can be linked to the concept of continuous improvement. 


\section{CONCLUSION}

This study has attempted to report issues relating to the acceptability and the applicability of the Lean Six Sigma initiative within a developing economy, exposing factors as they affect implementation. The themes presented in table 1 were deduced from responses from interviews conducted with LSS consultants in Nigeria. These factors generated from the identified themes as highlighted in table 1 exposes issues that affect the acceptability of the LSS initiative, namely the Certification-driven market, LSS receptivity/ perception, the Sustainability of LSS, the Nigerian environment and culture are among core factors to be considered for successful implementation of Lean Six Sigma. The practice and implementation of LSS in organizations has been proven to yield tremendous gains as shown in previous research. These gains are however not immediate, and the benefits not tangible in the short run. Like other quality improvement techniques, this study shows that LSS is saddled with some hindrances not only to its implementation but also to its sustainability. These hindrances are more pronounced in developing nations such as Nigeria where limited resources, frequently compete for many activities. The gains of implementing LSS cannot be overemphasized but for its success to be tangible there has to be a paradigm shift. This shift entails restructuring the application of LSS to fit environmental conditions, a shift in managements understanding and commitment, a shift in employee's perception of change, a change in the culture and attitude of employers of labor, a de-emphasis on substance and emphasis on value. It is imperative for organizations in Nigeria to clearly understand that LSS is not a short term solution but must be embraced as a culture to reap maximum benefits.

\section{REFERENCES}

[1]. Antony, J., J.L. Escamilla, and P. Caine, Lean Sigma [production and supply chain management]. Manufacturing Engineer, 2003. 82(2): p. 4042.

[2]. Bisgaard, S., Quality management and Juran's legacy. Quality Engineering, 2008. 20(4): p. 390-401.

[3]. Daunoriene, A. and D. Bagdoniene, Peculiarities of Business Process Management when Developing Quality Management System in Organizations. Economics \& Management, 2008: p. 801-807.

[4]. Psychogios, A.G. and L.K. Tsironis, Towards an integrated framework for Lean Six Sigma application: Lessons from the airline industry. Total Quality Management \& Business Excellence, 2012. 23(3-4): p. 397-415.

[5]. Antony, J., Lean and Six Sigma methodologies in NHS Scotland: Some observations and key findings from a Pilot Survey. IIE Annual Conference. Proceedings, 2008: p. 433-439.

[6]. Alsmadi, M., B. Lehaney, and Z. Khan, Implementing Six Sigma in Saudi Arabia: An empirical study on the fortune 100 firms. Total Quality Management \& Business Excellence, 2012. 23(3/4): p. 263-276.

[7]. Desai, D.A., A. Jiju, and M.B. Patel, An assessment of the critical success factors for Six Sigma implementation in Indian industries. International Journal of Productivity and Performance Management, 2012. 61(4): p. 426-444.
[8]. Deshmukh, S.V. and A. Chavan, Six Sigma and SMEs: a critical review of literature. International Journal of Lean Six Sigma, 2012. 3(2): p. 157-167.

[9]. Atkinson, P. and L. Nicholls, Demystifying Lean Culture Change' and continuous improvement. (cover story). Management Services, 2013. 57(3): p. 10-15.

[10]. Akbulut-Bailey, A.Y., J. Motwani, and E.M. Smedley, When Lean and Six Sigma converge: a case study of a successful implementation of Lean Six Sigma at an aerospace company. International Journal of Technology Management, 2012. 57(1-3): p. 18-32.

[11]. Laureani, A., Critical success factors for the effective implementation of Lean Sigma: Results from an empirical study and agenda for future research. International Journal of Lean Six Sigma, 2012. 3(4): p. 274283.

[12]. Timans, W., et al., Implementation of Lean Six Sigma in small-and medium-sized manufacturing enterprises in the Netherlands. The Journal of the Operational Research Society, 2012. 63(3): p. 339-353.

[13]. Laureani, A. and A. Jiju, Critical success factors for the effective implementation of Lean Sigma. International Journal of Lean Six Sigma, 2012. 3(4): p. 274-283.

[14]. Arnheiter, E.D. and J. Maleyeff, The integration of lean management and Six Sigma. The TQM Magazine, 2005. 17(1): p. 5-18.

[15]. Assarlind, M., I. Gremyr, and K. Bäckman, Multi-faceted views on a Lean Six Sigma application. International Journal of Quality \& Reliability Management, 2012. 29(1): p. 21-30.

[16]. Henderson, K.M. and J.R. Evans, Successful implementation of Six Sigma: benchmarking general electric company. Benchmarking: An International Journal, 2000. 7(4): p. 260-282.

[17]. Ferdousi, F. and A. Ahmed, How Becoming Lean Can Improve Performance: A Study on Bangladeshi Garment Industry. Prabandhan: Indian Journal of Management, 2010. 3(9): p. 36-42.

[18]. Kumar, M., et al., Implementing the Lean Sigma framework in an Indian SME: a case study. Production Planning \& Control, 2006. 17(4): p. 407423.

[19]. Jeyaraman, K. and L.K. Teo, A conceptual framework for critical success factors of lean Six Sigma: Implementation on the performance of electronic manufacturing service industry. International Journal of Lean Six Sigma, 2010. 1(3): p. 191-215.

[20]. Rockart, J.F., Chief executives define their own data needs. Harvard Business Review, 1979. 57(2): p. 81-93.

[21]. Fryer, K.J., A. Jiju, and A. Douglas, Critical success factors of continuous improvement in the public sector. The TQM Magazine, 2007. 19(5): p. 497-517.

[22]. Antony, J., et al., Lean Six Sigma for higher education institutions (HEIs)Challenges, barriers, success factors, tools/techniques. International Journal of Productivity \& Performance Management, 2012. 61(8): p. 940-948.

[23]. Goodman, M.R.V., The pursuit of value through qualitative market research. Qualitative Market Research: An International Journal, 1999. 2(2): p. 111-120.

[24]. Coldwell, D., Is research that is both causally adequate and adequate on the level of meaning possible or necessary in business research? A critical analysis of some methodological alternatives. Electronic Journal of Business Research Methods, 2007. 5(1): p. 1-10.

[25]. Collis, J. and R. Hussey, Business research: A practical guide for undergraduate and postgraduate students. 2009: Palgrave Macmillan.

[26]. Yin, R.K., Case study research: Design and methods. Vol. 5. 2009: sage.

[27]. Bryman, A., Integrating quantitative and qualitative research: how is it done? Qualitative research, 2006. 6(1): p. 97-113.

[28]. Chinelo, N.G., O. Munirat, and E.-I. Ronald, Management research and the phenomenon of industry growth: The case of Nigerian banking 
industry. Journal of Economics and International Finance, 2013. 5(2): p. $35-42$.

[29]. Evans, O., Correlations between the Petroleum Industry and the Per Capita Income in Nigeria: Cointegration and Error Correction Model Approach by Olaniyi Evans. 2013.

[30]. Euromonitor, Nigeria: Country Profile. 2014: Global Market Information Database.

[31]. Chete, L., et al., Industrial development and growth in Nigeria: Lessons and challenges. 2014, WIDER Working Paper.

[32]. Dibia, I.K. and S. Onuh, Lean Six Sigma deployments in agile industrial environment: the key factors. International Journal of Agile Systems and Management, 2012. 5(4): p. 330-349.

[33]. Tushman, M.L. and C.A. O'Reilly, Winning through innovation: A practical guide to leading organizational change and renewal. 2013: Harvard Business Press.

[34]. Kotter, J.P. and L.A. Schlesinger, Choosing strategies for change. Harvard business review, 2008. 86(7/8): p. 130.

\section{BIOGRAPHY}

Umude-Igbru Oviri C. received his B.Eng. in Mechanical Engineering from the Federal University of Technology Owerri, Nigeria in 2008 and obtained his Master degree in Engineering and Management in 2012 from Coventry University, United Kingdom. He is currently pursuing his $\mathrm{PhD}$ in Engineering Systems and Management at Aston University, United Kingdom. His area of interest includes Continuous Improvement, Lean Manufacturing, Six Sigma and Operations Management.

Brian Price is a lecturer in the Department of Engineering Systems and Management at Astopn University. He has about 25 years industrial experience, holding a variety of senior engineering leadership positions, including responsibilities for engineering development, project execution and business leadership, with consulting and manufacturing companies. His research interests include areas of, Product development decision making, Engine architecture analysis, Engineering project management best practiceProduct user profiles and duty cycle development.
Umude-Igbru, O \& Price, B 2015, 'Acceptability of Lean Six Sigma in a developing economy: results from exploratory research in Nigerian consulting companies'. in 2015 international conference on industrial engineering and operations management (IEOM) proceeding papers. IEEE, 5th International Conference on Industrial Engineering and Operations Management, IEOM 2015, Dubai, United Arab Emirates, 3-5 March. 